\title{
LA UNIVERSIDAD LATINOAMERICANA Y LA ECLOSION PEDAGOGICA
}

LUIS ALBERTO WARAT

Director del Instituto de Lógica Y Metodologia de la Universidad de Morón, Professor de Filosofia del Derecho e Introducción en la Universidad de Buenos Aires.

1 - Se trata en esie trabajo de partir, no de supuestos, teóricos, sino de la problemática metodológica que como docente me toca vivir y del intercambio de ideas y experiencias efectuadas profesores latinoamericanos; hechos, todos ellos, que vuelven necesarias algunas consideraciones en torno a la metodolog!a de la enseñanza del Derecho.

El tema es sumamente complejo, no existen recetas fijas, ni posibilidades de utilizar la misma estrategia en todos los paí. ses; con rodo, intentaremos, a partir de la experiencia argentina, puntualizar lo que podríamos denominar: NOTAS PARA LA TRANSFORMACION DE LA ENSEÑANZA JURIDICA. El valor de estas notas sería fundamentalmente sugerente, pueden dar pie a un diálogo fruetífero; a una adecuada proyección al plano jurídico de los últimos logros de la pedagogia y la psicologia del aprendizaje. Desde luego, en este período resulta muy recomendable la puesta en crisis y problematización de las estructuras tradicionales de nuestra enseñanza jurídica encaminada mas a la formación receptiva de conocimientos abstractos y técnicos que a la formación de profesionales aptos para actuar en el medio social con um pleno conocimiento de él.

El camino de las soluciones no es nada sencillo; no se cuentan con los recursos ambientales, técnicos y humanos para el cambio total. Ni los docentes ni los alumnos se encuentran masivamente preparados para la concretización de un violento replanteamiento total.

2 - Siguiendo a JEAN PIAGET, podria decirse, para comenzar estas notas, que en la enseñanza el primer defecto a superar es el de la ignorancia de los resultados de nuestras estrategias edı- 
cativas; nada preciso sabemos acerca de lo que subsiste de la enseñanza universitaria luego del egreso. Se nos dice que el Derecho Romano, o cualquier otra rama, es indispensable para la formación del abogado, pero nadie se ha preocupado por evaluar qué queda de esa formación en la mente del graduado. Nadie ha emprendido ningún estudio serio para saber si algunas de las enseñanzas "desprovistas hasta la evidencia" de todo valor formativo logran los fines utilitarios atribuídos. Realmente en qué reglas pedagógicas se basa la memorización de los códigos? Y qué comprobaciones se han realizado para constatar su valor formativo?

En general se cree que el acto de un examen es suficiente aval para la perdurabilidad del conocimiento, pero el examen final en nada resuelve el problema de la determinación del saldo educativo de los conocimientos memorizados después de varios años.

Los examenes finales muchas veces distorsionan la tarea educativa. El alumno esíudia presionado porla preocupación del examen alejado de la posibilidad de efectuar un análisis óntico y reflexivo del material informativo. Está claro, entonces, que deberia intentarse realizar un estudio pedagógico del rendimiento de cursos sin exámenes donde el estudiante es evaluado basicamente en función del trabajo diario y de su capacidad reflexiva y comparar el resultado con el dado por cursos en donde sólo rinden pruebas finales.

3 - Las reflexiones anteriores nos colocan ante otro tema candente de nuestro sistema universitario que se refiere a las formas de evaluación.

En el apartado anterior hemos asumido que las técnicas de evaluación eran un instrumento que los docentes utilizan con escasos y pocos resultados científicos para constatar la perdurabilidad de la información.

Los docentes no pueden ser ni imparciales ni objetivos ya que evalúan a través de pautas subjetivas, lo que conduze a una actitud generalmente autoritaria y por tanto sumamente desalentadora para los alumnos. Lejos estamos no sólo de saber si el conocimiento perdura o no, sino de haber constatado objetiva e imparcialmente si la información ha sido asimilada.

Aparentemente, sin necesidad de grandes sondeos, parece que nuestros sistemas tradicionales de evaluación fracasan; no por nada se dice que un graduado necesita diez años mas para 
ser realmente un profesional apto. La universidad, en descargo se dice, también brinda un buen arsenal lógico, arma a la que podríamos llamar una "mentalidad jurídica", ésto sin embargo nunca se ha rigurosamente constatado.

El camino de superación parece indicar la necesidad de fijar pautas de evaluación explícitas, claras, objetivas y uniformes dentro de las cátedras y la universidad. Una clara toma de conciencia de que el examen debe ser también una situación de aprendizaje mas, y a partir de alli estudiar con rigor científico las técnicas mas apias, descubrir si conviene el examen final o no y si el examen final debe ser la única opición o debe ser completada con otras técnicas: pruebas objetivas monográficas, tareas grupales por ciclos colectivos, etc. La decisión no deberá basarse exclusivamente en la comprobación de los resultados inmediatos sino en las aptitudes que los alumnos demuestren poseer en el futuro para los distintos fines de educación.

Los docentes deben tener un claro convencimiento de que la evaluación no es un fin em si mismo, que no pueden impartir enseñanza en función de una nota; que deben asumir una técnica evaluativa al servicio de los modernos instrumentos pedagógicos, que tienden a la coparticipación de los alumnos en el aprendizaje.

4 - Interesa también apuntar con PIAGET la necesidad de una rigurosa determinación de las finalidades de la educación impariida a las nuevas generaciones; que esos fines fueron construídos a partir de la posesión de estudios objetivos sobre las vinculaciones entre la educación y la sociedad de un adecuado estudio psicológico para saber si se han utilizado los medios adecuados para implementar esas finalidades. Se hace necesario, en suma, la urgente proyección al plano jurídico de una sociologia educativa que nos marque la dinámica de los grupos universitários, su estratificación categorial, la movilidad social dentro de las perspectivas de educación, la economia de la educación, un estudio sistemático del condicionamiento social de los sisiemas educativos.

5 - La elección de los métodos didácticos en las escuelas de derecho descansan basicamente en la creencia de que la metodologia del codificador es también una buena técnica educativa. Los docentes se limitan así a glosar a los codificadores sin tomar en cuenta la naturaleza de la inteligencia, el papel de 
la experiencia en la formación del conocimiento y los mecanismo de transmisión aptos para los adultos.

El método de transmisión tradicional en nuestras universidades descansa en las llamadas clases magistrales - conferencias con un auditorio pasivo que recibe el conocimiento pontificado a través de um juicio de valor ya consumado, una estructusra de valores simplesmente aceptados. La enseñanza impartida a través de estas clases, conferencias, apunta principalmente a la fijación reiterativa de la información.

La mayoria de las clases magistrales son preparadas por los docenies atendiendo mas a los efectos oratorios que a reales necesidades de comunicación.

Sin un proceso de asimilación dinâmica, la gravitación docente es prácticamente nula. La labor docente no descansa en suministrar información, para éso debende prepararse buenos libros didácticos que en derecho escasean, sino en desarrolar la inteligencia, para lo que es preciso entender que la inteligencia no descansa en respuestas asociativas sino a una dinámica transformación vinculada a la acción, conocer - dice PIAGET, es, pues, asimilar lo real a estructuras de transformaciones que son las estructuras que elabora la inteligencia como prolongación directa de la acción.

El conocimiento seria asi una surste de acción interiorizada, reflexiva y estructurada y no una copia reiterativa.

Toda asimilación, agrega PIAGET, es una reconstrucción o una reinvención. Los métodos didácticos deben descansar en los aportes de la psicologia educativa que faciliten y no frustren esos procesos de reconstrucción raciona!. Los métodos de transmisión otral basados en la lección infuitiva del maestro debendejar paso a los resultados de las rigurosas investigaciones psicopedagógicas.

6 - No puede existir una ciencia del derecho, sin rigor, sin una adecuada sistematización de las proposiciones descriptivas de los fenómenos jurídicos. De ahí, la importancia proclamada en dotar a los alumnos de derecho de un apropiado arsenal metodológico que les posibilite el aprendizaje coherente y riguroso de las distintas ramas de la jurisprudencia. De esa manera, se proporciona a los alumnos, a nivel curricular, un instrumento apropiado para la tarea crítica y reflexiva, que permile además la formación de profesionales aptos para influir en el desarrollo, cambio y transformación de nuestra so- 
ciedad. Sin este arsenal conceptual tampoco podrá alcanzarse la actitud estructuradora de nuestra inteligencia.

7 - El problema sin embargo no es sólo de formas en la comunicación sino también de contenidos. El problema es epistemológico, pues asimismo están perimidas ciertas reglas de la investigación jurídica. A este nivel debe comenzarse por la reivindicación del valor de una teoria general del derecho, de una teoria que clarifica la funcionalidad meramente didáctica de muchos conceptos revestidos de ingeniosas actitudes ontológicas.

8 - Hemos planteado hasta aqui algunos problemas de la enseñanza actual del derecho en lo que hace a la bibliografia, los programas y las técnicas de evaluación. De ningún modo puede aceptarse que los problemas de cada una de estas esferas puedan solucionarse si no se comienza con un cambio de mentalidad en los docentes por una toma de conciencia de las necesidades de cambio, que acepten la carencia, en lo general, de preparación pedagógica y la necesidad de recibir un adiestramiento actualizado en las técnicas modernas de aprendizaje. La prioridad máxima de la enseñanza del derecho estriba en la necesidad de aprender o enseñar no basta la vocación o el amor al derecho sino que ella debe ir acompañada de una adecuada planificación psicopedagógica.

No puede enseñarse bien o mal intuitivamente. No puede aceptarse sin mas la afirmación de que un gran jurista es un gran pedagogo.

El objetivo primordial de este trabajo es contribuir a tal toma de conciencia. El docente debe por tanto encontrar nuevos roles, un delicado equilibrio entre la transmisión informatıva y la acción, entre la investigación monográfica y la discusión entre el trabajo individual y el grupal.

Creo que todos debemos entender que el centro de la clase no es el profesor sino el tema grupalmente analizado. A partir de esto puede comenzar una fructífera renovación de los métodos educativos. De esa forma la eclosión pedagógica comenzará a dar sus frutos en el derecho. 